\title{
KNOWLEDGE, ATTITUDE, AND PRACTICE TOWARD PHARMACOVIGILANCE AND ADVERSE DRUG REACTION REPORTING AMONG NURSING STAFF AND STUDENTS
}

\author{
DHARINI B ${ }^{1 *}$, NAGARJUNA REDDY $\mathrm{V}^{2}$, DEEPALAKSHMI ${ }^{3}$, PRAMOD KUMAR A ${ }^{4}$ \\ ${ }^{1}$ Department of Pharmacovigilance, SDSTRC and Rajiv Gandhi Institute of Chest Diseases. Bengaluru, Karnataka, India. ${ }^{2}$ Indira Gandhi \\ Institute of Child Health, Bengaluru, Karnataka, India. ${ }^{3}$ Department of Pharmacy Practice, JSSCP, Ooty, Tamil Nadu, India. ${ }^{4}$ National \\ Coordination Center - Pharmacovigilance Programme of India, Indian Pharmacopoeia Commission, Ghaziabad, Uttar Pradesh, India. \\ Email: Dhariniboopathi92@gmail.com
}

Received: 21 September 2017, Revised and Accepted: 24 November 2017

\section{ABSTRACT}

Objective: The objective of this study is to assess awareness of Pharmacovigilance among the healthcare professionals and to evaluate the impact of an educational intervention for improving awareness of Pharmacovigilance among the nursing staff and nursing students from Bengaluru, Karnataka, India.

Methods: A cross-sectional study was carried out using a validated questionnaire that included demographic details and 20 survey items to evaluate the participants' knowledge, attitude, and perception (KAP) on adverse drug reactions (ADRs) and Pharmacovigilance. All participants received an interactive educational intervention in the form of a lecture. A pre- and post-KAP questionnaire survey was used to evaluate the impact of educational intervention among the participants. The Statistical Package for Social Sciences statistical software, version 16, was used to analyze the data.

Results: A total of 103 healthcare professionals in the study responded to the pre- and post-KAP survey questionnaires. 66 nursing students and 37 nursing staff were involved in the study. The increased awareness among the study subjects about pharmacovigilance between pre- and postintervention was statistically significant $(\mathrm{p}<0.001)$ which showed the effectiveness of educational intervention carried out.

Conclusion: The results show that participants in the study were only moderately aware of ADR monitoring. However, they had expressed a positive attitude toward Pharmacovigilance and ADRs reporting. There is a need to create awareness among the nursing fraternity about ADR reporting for improving the spontaneous reporting.

Keywords: Pharmacovigilance, Knowledge, Attitude, and perception questionnaire, Adverse drug reactions.

(c) 2018 The Authors. Published by Innovare Academic Sciences Pvt Ltd. This is an open access article under the CC BY license (http://creativecommons. org/licenses/by/4. 0/) DOI: http://dx.doi.org/10.22159/ajpcr.2018.v11i3.22700

\section{INTRODUCTION}

The two major concerns of a drug are safety and efficacy. The efficacy of a drug can be quantified with relative ease; the same cannot be said about safety. This is because the adverse effect of a drug may be uncommon (very serious) and many patients may be affected or subjected to a potential risk before the relationship with the drug is established $[1,2]$. The World Health Organization (WHO) has defined adverse drug reaction (ADR) as "a response to a drug which is noxious and unintended and which occurs at doses normally used in man for prophylaxis, diagnosis, or therapy of disease or for the modification of physiologic function"[3]. One of the important causes of morbidity and mortality worldwide is ADRs. Estimates suggest that ADRs are the fourth major cause of death in the United States recently [4]. The major key role in Pharmacovigilance programs is played by healthcare professionals such as physicians, pharmacist, and nurses [5,6], but with an estimated median underreporting rate (defined as the percentage of ADRs detected from intensive data collection that was not reported to relevant spontaneous reporting systems) of $94 \%$, it is noted that underreporting is very common [7], and occurs frequently for serious and unlabeled reactions $[8,9]$. The detection of important ADRs is delayed due to this. According to the studies from various settings, the inadequate knowledge and attitude of healthcare professionals about Pharmacovigilance are associated with a high degree of underreporting [10-15]. It is estimated that only $6-10 \%$ of all ADRs are reported $[16,17]$.

The word "Pharmacovigilance" is as follows: Pharmakon (Greek word for "drug") and vigilare (Latin word for "to keep watch") [18]. It is a growing discipline because of the rise of ADRs $[19,20]$ that ensure patient care and safety using the medicines in the best way for the treatment or prevention of ADRs [21]. Pharmacovigilance is defined by the WHO as "the science and activities relating to the detection, assessment, understanding, and prevention of adverse effects or any other possible drug-related problem, particularly long-term and short-term adverse effects of medicines" [22]. Due to the difference in drug response among individuals, various prescribing habits, drug regulatory system, and availability of drugs, it has been recommended for every country to set up their own Pharmacovigilance programs [23]. The common problem faced in Pharmacovigilance program is underreporting of ADRs [24,25]. Inadequate funds, lack of trained staff, and lack of awareness about detection, communication, and spontaneous monitoring of ADRs may be the reason, gross underreporting of ADRs is a cause of concern $[7,8]$. The success and effectiveness of any Pharmacovigilance system highly depend on the participation of all health care professionals, and thus, physicians, pharmacists, and nurses are also important healthcare professionals responsible for Pharmacovigilance activities and ADR reporting during their practice.

In India, Pharmacovigilance is still in early stage and there exists very limited knowledge about this discipline. Like most of the Pharmacovigilance programs around the world, even the Pharmacovigilance Program of India (PvPI) suffers from underreporting of ADRs by the healthcare professionals which leads in detecting important ADRs [26]. ADR monitoring centers (AMCs) in India are being set up across the country under PvPI reinitiated in 2010. This whole program is under the Central Drugs Standard Control 
Organization, Ministry of Health and Family Welfare, Government of India [27]. As per PvPI, it is mandatory for every teaching hospital to have a Pharmacovigilance center/cell. Therefore, this study was conducted among healthcare professionals to assess their awareness on Pharmacovigilance and to evaluate the impact of an educational intervention for creating awareness on Pharmacovigilance among nursing staff and student's in Bengaluru, Karnataka, India.

\section{METHODS}

\section{Study design and site}

A questionnaire survey was conducted in two tertiary care hospitals in Bengaluru, Karnataka, India.

\section{Source of data}

The required information for the study was obtained from nursing professionals and students of study site.

\section{Sample size}

This study involved 127 participants, of which only 103 (37 nursing staff and 66 nursing students) returned the filled pre- and postquestionnaire.

\section{Design of questionnaire}

Questionnaire containing 20 questions was given to all the participants. The questionnaire was designed in such a way to assess the demographic details of the participants and had three sections containing 11 knowledge-based, 5 attitudes-based, and 4 practice-related questions, respectively.

\section{Collection of data}

The pre-knowledge, attitude, and perception (KAP) questionnaire was initially administered to all 127 participants, and the purpose of the study was explained. A theoretical presentation on what is Pharmacovigilance, PvPI, ADRs (i.e., in terms of definition, causality assessment, and seriousness), role of nursing staff in reporting, importance of reporting the ADRs, and its effect on patient safety and various tools to report ADR (i.e., forms and mobile app) was used in the educational intervention. Following the educational intervention program on Pharmacovigilance conducted by the Pharmacovigilance associates of ADR monitoring center, all participants in the study were given post-KAP questionnaire and their responses were documented. A total of 5 intervention programs were conducted to cover the study population.

\section{Data analysis and statistics}

The scores of pre- and post-test questionaries' were analyzed to study the effectiveness of educational intervention among the participants. The pre-KAP questionnaire was analyzed question wise, and their percentage value was calculated. The Statistical Package for Social Sciences statistical software, version 16 , was used to analyze the data.

\section{Validation of questionnaire}

The questionnaire was a 20 item inventory titled "The standard KAP questionnaire" which was validated at one of the site. It contained 20 items that were adapted from the previous studies and literature.

\section{RESULTS}

The present study involved 103 (81.1\%) participants from 127, who participated and responded.

Categorization on the demographic details of the participants involved in the study was done based on gender distribution, professional status, and experience. The thoroughly analyzed results are reported in Tables 1 and 2.

The KAP of the participants toward Pharmacovigilance and ADR reporting was evaluated by comparing the pre- and post-KAP percentage of responses. Table 3 contains a comparison of the values
Table 1: Participant's demographic details

\begin{tabular}{|c|c|c|c|}
\hline \multirow[t]{2}{*}{ Designation } & \multicolumn{2}{|c|}{ Gender distribution } & \multirow{2}{*}{$\begin{array}{l}\text { Total number } \\
\text { of participants } \\
\text { n=103 (\%) }\end{array}$} \\
\hline & Male (\%) & Female (\%) & \\
\hline $\begin{array}{l}\text { B.Sc. nursing } \\
\text { students }\end{array}$ & $4(6.06)$ & $62(93.94)$ & $66(64.07)$ \\
\hline Nursing staff & 8 (21.62) & 29 (78.38) & 37 (35.93) \\
\hline Total & $12(11.66)$ & 91 (88.34) & 103 \\
\hline
\end{tabular}

Table 2: Experience of the participants

\begin{tabular}{ll}
\hline$<10$ years & 82 \\
More than 10 years & 21 \\
\hline
\end{tabular}

and percentage of positive and negative responses for the pre- and post-KAP questionnaire, respectively.

The results of Q No-6,19 \& 20 are given in graphical representation as the participants were allowed to choose multiple answers.

Fig. 1 gives a detailed overview of the responses for the knowledgebased question No 6. Participants were allowed to choose more than one option. The respondents' knowledge toward reporting of ADRs based on the seriousness indicates that they preferred to report serious and life-threatening cases $41.74 \%$ in the pre-questionnaire, which eventually changed in the post-questionnaire outcome, suggest that all ADRs must be reported irrespective of seriousness $87.37 \%$.

The participants reason cited for not reporting ADRs and practicebased Q-19 are listed in Fig. 2. Lack of knowledge (48.54\%) and whom to report $(28.15 \%)$ the ADR, difficulty to pinpoint suspected drug (34.95\%), and busy schedule (32.03\%) were the main reasons cited before the educational intervention.

Methods preferred for ADR reporting practice-based Q 20 are depicted in Fig. 3. Opinion on their preferred mode of reporting was sought from the respondents. Most preferred was direct contact $60.19 \%$ preKAP. Post-KAP results show interest in reporting through Android application $32.03 \%$ and Email $27.18 \%$.

\section{DISCUSSION}

It is not possible to prevent every ADR, but the knowledge of nursing staff in this field is very effective to decrease the rate of occurrence of ADRs [28]. It is important for the nursing staff to participate in spontaneous reporting scheme because they spend more time in the wards and it is most likely that any acute ADR will first be observed by them. In countries where nurses are already participating in the ADR reporting scheme, studies have shown that they indeed contribute positively toward the promotion of ADR reporting [29,30]. Shalini and Mohan [31] and Arjun et al. [32] studies have suggested that the percentage of awareness among the dental and nursing staff was surprisingly negligible and increasing awareness in nursing students and nursing staff can increase the number of ADR reports. In our study, one focus of educational intervention was to increase awareness in nursing professionals on Pharmacovigilance and PvPI, as they can play an important role in making the Pharmacovigilance program more efficacious since their work nature involves close contact with the patients for a longer duration [33]. The increase in the positive response in pre- and post-KAP questions (1-20) of the standard KAP questionnaire was clearly evident. The participants' response on question 01 and 02 were $49.51 \%-80.58 \%$ after the intervention and $16.50 \%-74.75 \%$ after the intervention, respectively.

Fig. 1 shows a positive response to educational intervention suggesting that $87.73 \%$ post-KAP response on reporting all ADRs. The percentage of overall respondents who realized the importance of ADR reporting increased from $70 \%$ to $97 \%$ from pre intervention to post intervention. 


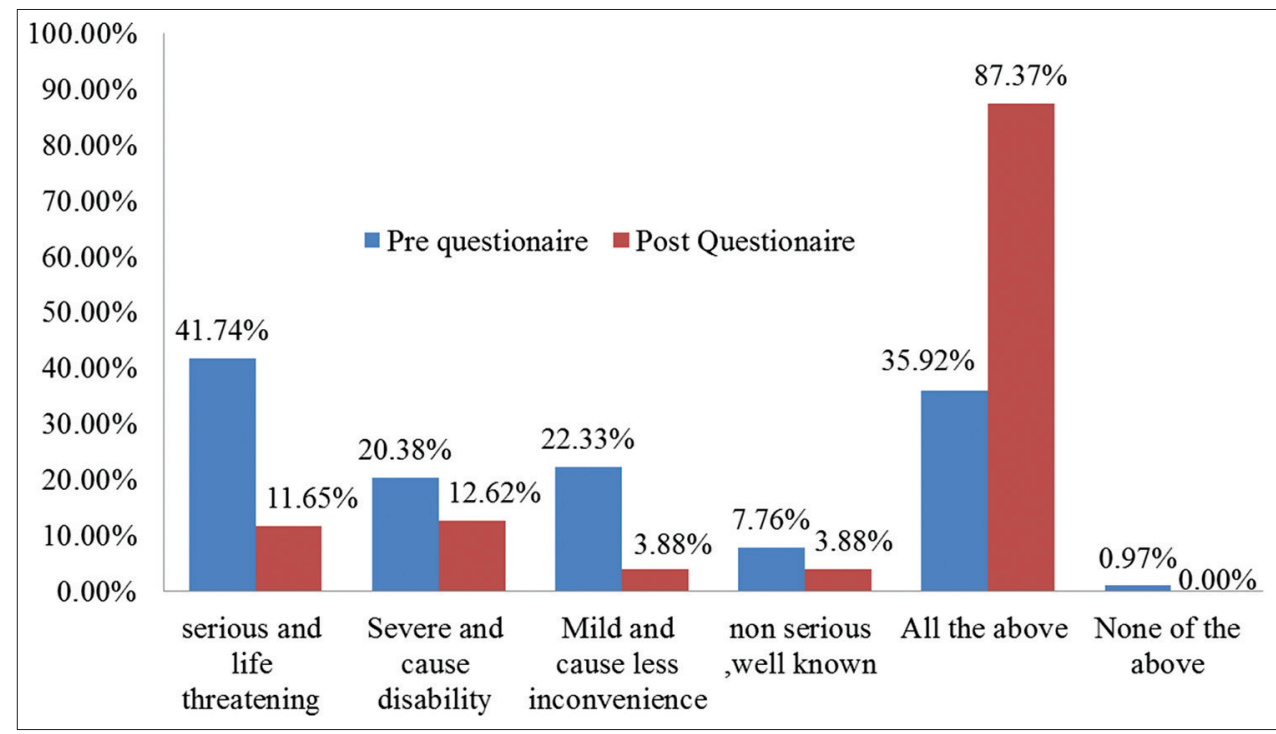

Fig. 1: Adverse drug reactions should be reported only when they are?

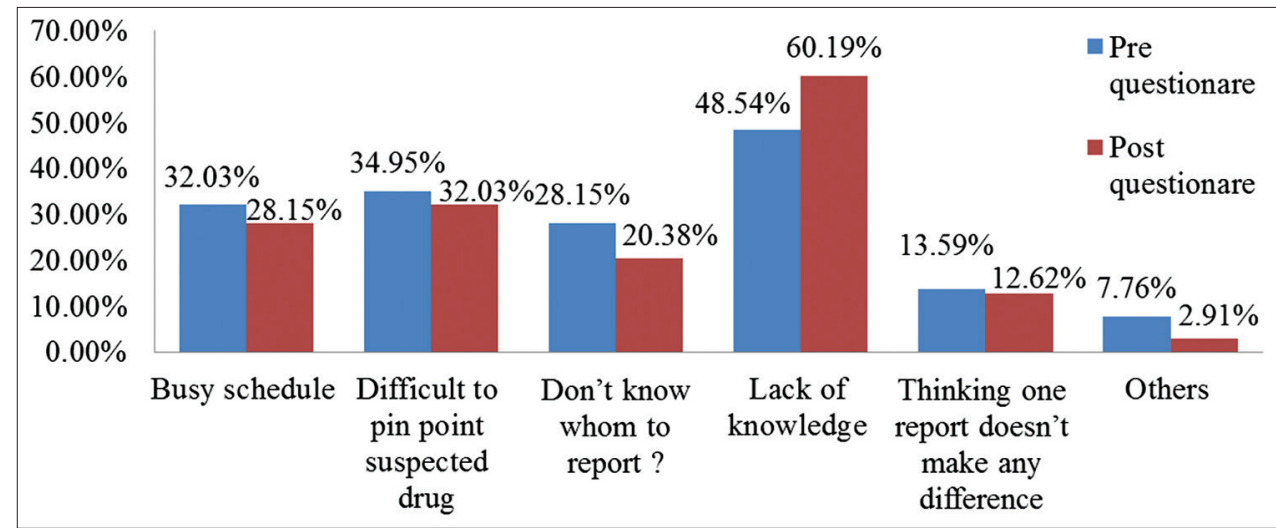

Fig. 2: Factors responsible for underreporting of adverse drug reaction's

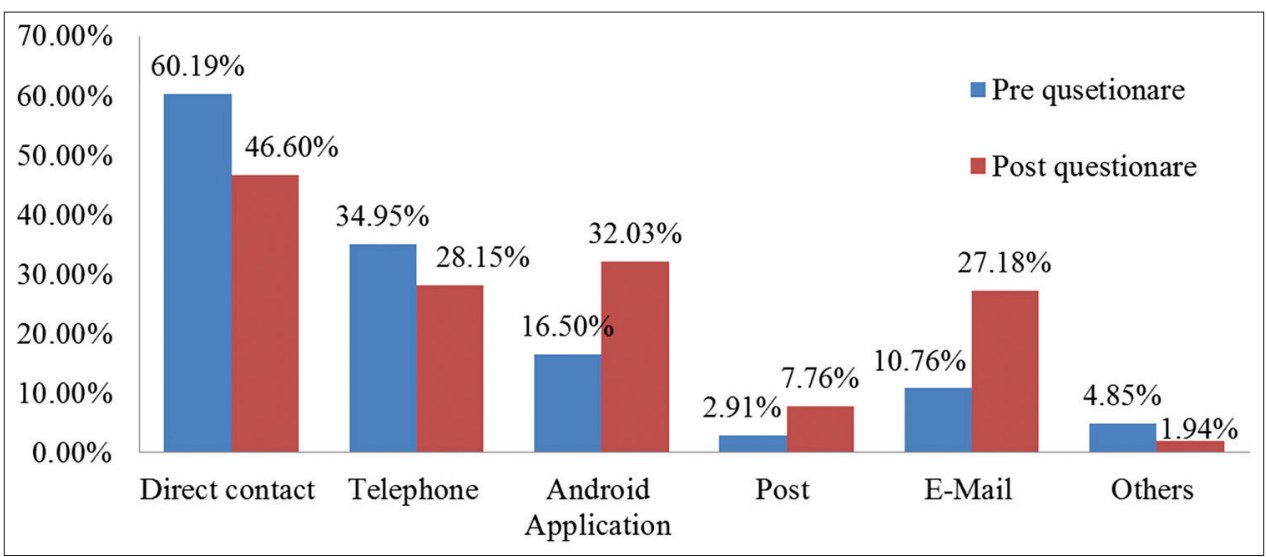

Fig. 3: Methods preferred to report adverse drug reactions

This shows that the educational intervention was well received by the participants. Question No -8 shows that $56 \%$ of staff and $24 \%$ of students answered yes in pre-KAP to $91 \%$ of staff and $89 \%$ of student post-KAP. Kamtane and Jayawardhani also shows that a significant number of the respondents were not aware of the existence of a national Pharmacovigilance center in India [34]. The lack of awareness of participants about the existence of the PvPI and ADR reporting system (Table 3) is reflected in the result, which would ultimately affect the reporting. Therefore, personal communication and advertisement appear necessary to enhance reporting and create awareness about Pharmacovigilance program and AMC's. Question 9 shows statistically significance at $\mathrm{p}<0.001$; The knowledge about the existence of nearby AMC found increased from $26.21 \%$ at prior to intervention to $73.78 \%$ post intervention. As per Gupta et.al [35] study, many healthcare professionals $(75.51 \%)$ accepted that reporting ADR and teaching healthcare professionals on Pharmacovigilance are necessary. The 
Table 3: Pre- and post-KAP evaluation

\begin{tabular}{|c|c|c|c|c|}
\hline Q No & KAP & Pre-KAP responses $(\%)$ & Post-KAP responses $(\%)$ & p value \\
\hline \multirow[t]{3}{*}{1} & Are you familiar with the term Pharmacovigilance? & & & $<0.0001$ \\
\hline & Yes & $51(49.51)$ & $83(80.58)$ & \\
\hline & No & $52(50.49)$ & $20(19.41)$ & \\
\hline \multirow[t]{5}{*}{2} & Pharmacovigilance is the study that relates to: & & & \\
\hline & Safe, effective, appropriate, and economic use of medicines & $6(5.82)$ & $3(2.91)$ & $<0.0001$ \\
\hline & Therapeutic drug monitoring & $3(2.91)$ & 0 & \\
\hline & $\begin{array}{l}\text { Detection, assessment, understanding, and prevention of adverse } \\
\text { effectsW }\end{array}$ & $17(16.50)$ & $77(74.75)$ & \\
\hline & All the above & $77(74.75)$ & $23(22.33)$ & \\
\hline \multirow[t]{3}{*}{3} & Do you believe all the drugs available in the market are safe? & & & 0.0449 \\
\hline & Yes & $8(7.76)$ & $13(12.62)$ & \\
\hline & No & $95(92.24)$ & $90(87.38)$ & \\
\hline \multirow[t]{3}{*}{4} & Do you think ADR reporting is important? & & & \\
\hline & Yes & $72(69.90)$ & $100(97.05)$ & 0.0282 \\
\hline & No & $31(30.10)$ & $3(2.92)$ & \\
\hline \multirow[t]{2}{*}{5} & Should ADRs be reported only by physicians? & & & \\
\hline & No & $19(18.45)$ & $43(41.74)$ & \\
\hline \multirow[t]{3}{*}{7} & Are you aware of any drug that has been banned due to ADR? & & & \\
\hline & Yes & $22(21.35)$ & $89(86.40)$ & $<0.0001$ \\
\hline & No & $81(78.64)$ & $14(13.60)$ & \\
\hline \multirow[t]{5}{*}{8} & Are you aware of Pharmacovigilance Program of Indian & & & \\
\hline & Pharmacopeia commission, Ministry of Health, Government of & & & \\
\hline & India? & & & \\
\hline & Yes & $37(35.92)$ & $93(90.29)$ & $<0.0001$ \\
\hline & No & $66(64.08)$ & $10(9.71)$ & \\
\hline \multirow[t]{3}{*}{9} & $\begin{array}{l}\text { Is there any nearby ADR reporting and monitoring center in your } \\
\text { knowledge? }\end{array}$ & & & \\
\hline & Yes & $27(26.21)$ & $76(73.78)$ & $<0.0001$ \\
\hline & No & $76(73.78)$ & $27(26.21)$ & \\
\hline \multirow[t]{3}{*}{10} & Are you aware of PvPI android application? & & & \\
\hline & Yes & $7(6.79)$ & $82(80.58)$ & $<0.0001$ \\
\hline & No & $96(93.21)$ & $20(19.42)$ & \\
\hline 11 & Are you aware of PvPI toll-free number? & & & \\
\hline \multirow[t]{3}{*}{12} & Do you think reporting ADR is necessary? & & & \\
\hline & Yes & $79(76.69)$ & $101(98.10)$ & $<0.0001$ \\
\hline & No & $24(23.31)$ & $2(1.90)$ & \\
\hline \multirow[t]{3}{*}{13} & Do you think reporting ADR will increase patient safety? & & & \\
\hline & Yes & $76(73.78)$ & $99(96.11)$ & $<0.0001$ \\
\hline & No & $27(26.21)$ & $4(3.89)$ & \\
\hline \multirow[t]{3}{*}{14} & $\begin{array}{l}\text { Do you worry about legal problems while you think of ADR } \\
\text { reporting? }\end{array}$ & & & \\
\hline & Yes & $62(60.19)$ & $24(23.30)$ & 0.0190 \\
\hline & No & $41(39.81)$ & $79(76.70)$ & \\
\hline \multirow[t]{5}{*}{15} & $\begin{array}{l}\text { What is your opinion about establishing ADR monitoring center in } \\
\text { every hospital? }\end{array}$ & & & \\
\hline & Should be in every hospital & $70(67.96)$ & $98(95.14)$ & $<0.0001$ \\
\hline & Not necessary in every hospital & $6(5.82)$ & 0 & \\
\hline & One in a city is sufficient & $4(3.88)$ & $2(1.94)$ & \\
\hline & Depends on number of bed size in the hospitals & $23(22.34)$ & $3(2.92)$ & \\
\hline \multirow[t]{3}{*}{16} & $\begin{array}{l}\text { Do you think Pharmacovigilance should be taught in detail to } \\
\text { healthcare professionals? }\end{array}$ & & & \\
\hline & Yes & $73(70.87)$ & $98(95.14)$ & $<0.0001$ \\
\hline & No & $30(29.12)$ & $5(4.86)$ & \\
\hline \multirow[t]{3}{*}{17} & Have you reported any ADR so far? & & & \\
\hline & Yes & $21(20.38)$ & $50(48.54)$ & $<0.0001$ \\
\hline & No & $82(79.62)$ & $53(51.46)$ & \\
\hline \multirow[t]{3}{*}{18} & Have you ever counseled the patient regarding ADRs? & & & \\
\hline & Yes & $26(25.24)$ & $61(59.22)$ & $<0.0001$ \\
\hline & No & $76(73.76)$ & $41(39.78)$ & \\
\hline
\end{tabular}

ADRs: Adverse drug reactions, PvPI: Pharmacovigilance Program of India, KAP: Knowledge, attitude, and perception

positive response rate of $76.69 \%$ before to $98.10 \%$ and $73.78 \%$ before to $96.11 \%$ after the educational intervention program, respectively, for question 12 and 13 indicates that participants felt that ADR reporting is necessary and thinks that it will increase patient safety. However, question 14 shows that legal fear for reporting needs to be changed. Nursing staff should accept ADR reporting as a professional obligation and overcome the fear. To remove misconceptions and modify, the attitude of nurses toward reporting personal discussions and awareness programs will be more helpful.

Question 15 shows that $95.14 \%$ of participants felt ADR monitoring center should be present in every hospital after the educational 
intervention. Question 16 shows that $70.87 \%$ pre-KAP to $95.14 \%$ post-KAP results suggest that all healthcare professionals should be educated in depth about Pharmacovigilance program. From our study, it has been noticed that a maximum number of participants are having a positive attitude toward Pharmacovigilance program which is a welcome sign toward PvPI. The actual reporting was very low, even when ADR reporting was considered to be important by a majority of the respondents. Previous studies also establish that underreporting of ADRs is a worldwide phenomenon $[7,11,35,36]$. While it is important to note that these studies were carried out among physicians, several other studies involving nurses have indeed confirmed that underreporting of ADRs is common to all healthcare professionals [31,32]. To improve the ADR reporting, there is a direct need of knowing the reasons for underreporting [37].

Fig. 2 shows the reasons for underreporting in our study, which was lack of knowledge, difficulty to pinpoint suspect drugs, and busy schedule. This was supported by the study conducted by Chatterjee et al. [38], which stated that the clinical negligibility of the adverse reaction due to lack of time and little knowledge about the types of reactions to be preferentially reported are the main reason for underreporting of ADRs. Fig. 3 shows the methods preferred for ADR reporting in which the results of pre-KAP show the lack of awareness in the participants about the existence of various reporting tools.

The post-KAP results reflect positive response toward using information technology in ADR reporting. The overall study findings suggest the need for periodic awareness programs for the healthcare professionals regarding the ADR monitoring program in the hospital and the ADR reporting procedure. This might encourage the healthcare professionals to actively participate in the ADR reporting.

\section{CONCLUSION}

The influence on ADR reporting strongly lies on the knowledge and attitudes. The lack of knowledge and negative perceptions about Pharmacovigilance and ADR reporting would lead to ADR underreporting. To resolve the deficits in the practice of ADR reporting among nursing staff, it is necessary to create awareness on the importance of reporting, the reporting system, and their obligation to report ADRs. Majority of respondents agreed that reporting of ADR and teaching healthcare professionals in detail about Pharmacovigilance are necessary. Further, our study strongly suggested that healthcare professionals, especially nursing staff, should be trained on ADR reporting since they are in closer association with patients.

\section{LIMITATION}

The present study was done only on nursing professionals from two hospitals. There is a scope for the study in larger group of nursing professional.

\section{ACKNOWLEDGMENT}

Logistic and technical support given by Pharmacovigilance Programme of India,IndianPharmacopoeia Commission, Ghaziabad, India.

\section{AUTHORS CONTRIBUTION}

Dharini and Nagarjuna reddy collected data and Pramod kumar and Deepalakshmi helped in statistics.

\section{CONFLICTS OF INTEREST}

None declared

\section{REFERENCES}

1. Lazarou J, Pomeranz BH, Corey PN. Incidence of adverse drug reactions in hospitalized patients: A meta-analysis of prospective studies. JAMA 1998;279:1200-5

2. Classen DC, Pestotnik SL, Evans RS, Lloyd JF, Burke JP. Adverse drug events in hospitalized patients. Excess length of stay, extra costs, and attributable mortality. JAMA 1997;277:301-6.

3. World Health Organization. Requirements for Adverse Reaction Reporting. Geneva, Switzerland: World Health Organization; 1975.

4. Hanafi S, Torkamandi H, Hayatshahi A, Gholami K, Javadi M. Knowledge, attitudes and practice of nurse regarding adverse drug reaction reporting. Iran J Nurs Midwifery Res 2012;17:21-5.

5. Ahmad SR. Adverse drug event monitoring at the food and drug administration. J Gen Intern Med 2003;18:57-60.

6. Wysowski DK, Swartz L. Adverse drug event surveillance and drug withdrawals in the united states, 1969-2002: The importance of reporting suspected reactions. Arch Intern Med 2005;165:1363-9.

7. Hazell L, Shakir SA. Under-reporting of adverse drug reactions: A systematic review. Drug Saf 2006;29:385-96.

8. Moride Y, Haramburu F, Requejo AA, Bégaud B. Under-reporting of adverse drug reactions in general practice. Br J Clin Pharmacol 1997; 43:177-81.

9. Heeley E, Riley J, Layton D, Wilton LV, Shakir SA. Prescriptionevent monitoring and reporting of adverse drug reactions. Lancet 2001;358:1872-3.

10. Figueiras A, Tato F, Fontaiñas J, Gestal-Otero JJ. Influence of physicians' attitudes on reporting adverse drug events: A case-control study. Med Care 1999;37:809-14.

11. Williams D, Feely J. Underreporting of adverse drug reactions: Attitudes of Irish doctors. Ir J Med Sci 1999;168:257-61.

12. Perlík F, Slanar O, Smíd M, Petrácek J. Attitude of Czech physicians to adverse drug reaction reporting. Eur J Clin Pharmacol 2002;58:367-9.

13. Belton KJ, Lewis SC, Payne S, Rawlins MD, Wood SM. Attitudinal survey of adverse drug reaction reporting by medical practitioners in the United Kingdom. Br J Clin Pharmacol 1995;39:223-6.

14. Hasford J, Goettler M, Munter KH, Müller-Oerlinghausen B. Physicians' knowledge and attitudes regarding the spontaneous reporting system for adverse drug reactions. J Clin Epidemiol 2002;55:945-50.

15. Herdeiro MT, Figueiras A, Polónia J, Gestal-Otero JJ. Physicians' attitudes and adverse drug reaction reporting: A case-control study in Portugal. Drug Saf 2005;28:825-33.

16. Smith CC, Bennett PM, Pearce HM, Harrison PI, Reynolds DJ, Aronson JK, et al. Adverse drug reactions in a hospital general medical unit meriting notification to the committee on safety of medicines. $\mathrm{Br} \mathrm{J}$ Clin Pharmacol 1996;42:423-9.

17. Feely J, Moriarty S, O'Connor P. Stimulating reporting of adverse drug reactions by using a fee. BMJ 1990;300:22-3

18. Shuka SS, Bina G, Pandey R, Rao SP, Singh V, Amber V. Importance of pharmacovigilance in Indian pharmaceutical industry. Asian J Res Pharm Sci 2012;2:4-8.

19. Von Laue NC, Schwappach DL, Koeck CM. The epidemiology of preventable adverse drug events: A review of literature. Wien Klin Wochenschr 2003;115:407-15

20. Wu WK, Pantaleo N. Evaluation of outpatient adverse drug reactions leading to hospitalization. Am J Health Syst Pharm 2003;60:253-9.

21. Aziz Z, Siang TC, Badarudin NS. Reporting of adverse drug reactions: Predictors of under-reporting in Malaysia. Pharmacoepidemiol Drug Saf 2007; 16:223-8

22. Olsson S. The need for pharmacovigilance. In: Gupta SK, editor. Pharmacology and Therapeutics in the New Millennium. New Delhi: Narosa Publishing House; 2001. p. 502-8.

23. Oshikoya KA, Awobusuyi JO. Perceptions of doctors to adverse drug reaction reporting in a teaching hospital in Lagos, Nigeria. BMC Clin Pharmacol 2009;9:14.

24. Green CF, Mottram DR, Rowe PH, Pirmohamed M. Attitudes and knowledge of hospital pharmacists to adverse drug reaction reporting. Br J Clin Pharmacol 2001;51:81-6.

25. Subish P, Izham M, Mishra P. Evaluation of the knowledge, attitude and practices on adverse drug reactions and pharmacovigilance among healthcare professionals in a Nepalese hospital: A preliminary study. Int J Pharm 2007;6:1-5.

26. Rajesh R, Vidyasagar S, Nandakumar K. Retracted by plagiarism: Highly active antiretroviral therapy induced adverse drug reactions in Indian human immunodeficiency virus positive patients. Pharm Pract (Granada) 2011;9:48-55.

27. Ministry of Health and Family Welfare, Government of India. Pharmacovigilance Programme of India 2010. CDSCO, Ministry of Health and Family Welfare, Government of India; 2010

28. Hajebi G, Mortazavi SA, Salamzadeh J, Zian A. A survey of knowledge, attitude and practice of nurses towards pharamacovigilance in Taleqani hospital. Iran J Pharm Res 2010;9:199-206.

29. Ulfvarson J, Mejyr S, Bergman U. Nurses are increasingly involved in pharmacovigilance in Sweden. Pharmacoepidemiol Drug Saf 
2007;16:532-7.

30. Backstrom M, Mjorndal T, Dahlqvist R. Spontaneous reporting of adverse drug reactions by nurses. Pharmacoepidemiol Drug Saf 2000;11:647-50.

31. Shalini S, Mohan S. A study on the awareness and attitude towards pharmacovigilance and adverse drug reaction reporting among nursing students in a private university, Malaysia. Int J Curr Pharm Res 2015;7:84-9.

32. Arjun TN, Sudhir H, Gouraha A, Jain S, Chavan K, Dayma A. Assessment of knowledge, attitude and practice related to pharmacovigilance among the healthcare professionals in a teaching hospital in central India: An questionnaire study. World J Pharm Pharm Sci 2015:4;785-99.

33. Patil A, Gurav YA, Thorat MB, Walsangikar SD. Survey of pharmacovigilance awareness among healthcare professionals. Int $\mathrm{J}$ Pharm Ther 2014;4:31-4.
34. Kamtane RA, Jayawardhani V. Knowledge, attitude and perception of physicians towards Adverse drug reaction reporting: A Pharmacoepidemiological study. Int J Pharm Pharm Sci 2012;4:698-704.

35. Gupta SK, Nayak RP, Shivaranjani R, Vidyarthi SK. A questionnaire study on the knowledge, attitude, and the practice of pharmacovigilance among the healthcare professionals in a teaching hospital in South India. Perspect Clin Res 2015;6:45-52.

36. Lopez-Gonzalez E, Herdeiro MT, Figueiras A. Determinants of underreporting of adverse drug reactions: A systematic review. Drug Saf 2009;32:19-31.

37. Sindhuja CH, Shafiya begum SK, Suryateja P, Sudha P. Knowledge, attitude and behavior of community pharmacists towards adverse drug reactions. Int J Pharm Pharm Sci 2015;7:258-61.

38. Chatterjee S, Lyle N, Ghosh S. A survey of the knowledge, attitude and practice of adverse drug reaction reporting by clinicians in eastern India. Drug Saf 2006;29:641-2. 